\title{
Feminilização e (Des)valorização do Trabalho das Mulheres: Papeis de Gênero e Neoliberalismo
}

\author{
Júlia Machado Dias ${ }^{1}$
}

\section{Resumo}

Este artigo tem o objetivo de abordar os impactos do neoliberalismo na transformação da categoria trabalho para as mulheres latino-americanas, evidenciando como as construções sociais em torno do feminino ainda hoje moldam a percepção social em termos de (des)valorização do trabalho das mulheres. Para isso, traremos a discussão de Zillah Eiseinstein acerca do capitalismo-patriarcal, debatendo os papeis fixados por este sistema para a subalternização das mulheres. Questões sobre a descolonização e despatriarcalização dos Estados trarão percepções sobre os direitos das mulheres num esforço de abordar os impactos dessa divisão sexual do trabalho na esfera pública, nos termos de cidadania e de justiça social de Nancy Fraser. Por último, serão consideradas as transformações na categoria trabalho para as mulheres latino-americanas com as políticas neoliberais de fins dos anos 1990, a partir da sociologia do trabalho. A divisão sexual do trabalho é fundamental para compreender a exclusão das mulheres da esfera pública a despeito de grandes conquistas obtidas pelos movimentos feministas e de mulheres. Os efeitos dessa forma organizativa são sentidos pelas mulheres no mercado de trabalho, em que a divisão sexual do trabalho atua abrindo o que parecem ser brechas para redução de desigualdade apesar de serem a perpetuação da opressão por outros meios. É o que aconteceu com a entrada massiva de mulheres em setores não tradicionalmente ocupados por elas nos fins dos anos 1990, através da redução de salários e prestígio social desses setores comparativamente com quando eram majoritariamente ocupados por homens.

Palavras-chave: capitalismo-patriarcal; neoliberalismo; mulheres.

\begin{abstract}
This article talks about the impacts of neoliberalism in the transformation of the labor category to Latin American women, highlighting how social constructions around the feminine still shape social perception in terms of (de)valorization of women's work. For this, we bring Eiseinstein's discussion of patriarchal capitalism to understand the roles set by this system around the subalternization of women. The debate on decolonization and depatrialization of states will bring insights on women's rights in an effort to address the impacts of this sexual division of labor in the public sphere in terms of citizenship and social justice by Nancy Fraser. Finally, we will consider the transformations in the category of work for Latin American women with the neoliberal policies of the late 1990s, based on the sociology of work. The sexual division of labour is fundamental to understand the exclusion of women from the public sphere despite great achievements of the feminist and women's movements. The effects of this organizational form are felt by women in the labor market,

\footnotetext{
1 Júlia Machado Dias é graduada em Relações Internacionais pela Universidade Federal de Uberlândia e mestranda em Relações Internacionais pela mesma instituição. Contato: julia.macdias@ gmail.com
} 
where the sexual division of labor acts by opening up what appear to be gaps to reduce inequality despite the perpetuation of oppression by other means. This is what happened to the massive entry of women into sectors not traditionally occupied by them in the late 1990s, through the reduction of wages and the social prestige of these sectors compared to when they were occupied mostly by men.

Key-words: capitalism-patriarchal; neoliberalism; women.

\title{
Introdução
}

\author{
Não existe imparcialidade. Todos são orientados por uma \\ base ideológica. A questão é: sua base é inclusiva ou \\ excludente? (Freire, s/a).
}

Os eventos históricos são comumente apontados como se fossem neutros e não tivessem impactos específicos a partir de gênero, raça, etnia, classe, diversidade sexual, por exemplo. Tickner (1997), autora feminista das Relações Internacionais, ao buscar um diálogo com os princípios que regiam a política para a perspectiva realista de Morgenthau, traz fortemente como esta é vivida e sentida de forma diferente entre homens e mulheres. Este aspecto, não abordado pelo autor, homogeneiza a política e perde elementos interessantes àquelas e aqueles que buscam trazê-la com vistas ao combate das discriminações e opressões.

Nesse sentido, compreendemos o neoliberalismo como discurso hegemônico de um modelo civilizatório: “(...) síntese dos tanto dos pressupostos quanto dos valores básicos da sociedade liberal moderna com relação ao ser humano, à riqueza, à história, ao progresso, ao conhecimento e à boa vida" (LANDER, 2005, p. 8). Assim, este artigo tem o objetivo de debater o que o neoliberalismo significa para as mulheres e para sua participação no mercado de trabalho tendo em vista a interseccionalidade, isto é, as lentes de gênero, raça, etnia, classe, diversidade sexual.

Tendo isso em vista, o presente trabalho buscará traçar um panorama relativamente breve sobre as diferentes construções sociais em torno do que é visto como "ser mulher", nas esferas públicas e privada e, por fim, no mercado de trabalho. O objetivo é desnudar algumas das relações de poder ocultas na divisão sexual do trabalho como sustentáculo de continuidade dessa domesticação das mulheres e do patriarcado, assim como das instituições também necessárias para a continuidade dessa forma de organização.

As construções sociais dos papeis de gênero influencia a redução em termos da 
percepção dos direitos das mulheres, bem como do escopo da democracia e da justiça social alcançada por meio dela. Abordaremos sobre despatriarcalização e descolonização dos Estados a partir de autoras como Dunia Mokranis e Luis Tapia, trazendo a perspectiva dos autores sobre a democracia liberal e a necessidade de repensá-la. Joan Scott nos ajuda a levantar questões de identidades de grupo e da igualdade a partir da diferença, enquanto Rita Segato aborda o caráter ainda colonial dos Estados. Por sua vez, o conceito de justiça social de Nancy Fraser nos auxilia na compreensão do que significa a busca por igualdade nas diferentes esferas da sociedade: sócioeconômica, cultural e política.

Mesmo sendo teorias de tradições distintas, acreditamos serem debates que dialogam entre si e contribuem para possibilitar uma visão mais complexa da situação das mulheres. Dunia Mokranis, Luis Tapia e Rita Segato trazem a perspectiva da teoria decolonial ${ }^{2}$, em que a colonização é entendida como um momento histórico que consolidou estruturas coloniais e colonialidades que se perpetuam ainda hoje. Para este texto utilizaremos suas ideias em torno da cidadania e da democracia liberal, com a proposta de compreender em que medida essa forma específica e ocidental de organização política corrobora com a subalternização das mulheres nas diferentes esferas da sociedade.

Por sua vez, Joan Scott é importante historiadora e aborda como grupos são e foram socialmente construídos ao longo da história, como forma de contrapor o indivíduo enquanto ideia abstrata e universal e demonstrar a exclusão das mulheres e outras chamadas minorias da esfera pública. A partir disso, Nancy Fraser traz reflexões importantes sobre a tridimensionalidade da justiça social compreendendo que a "mera" participação política das mulheres não implica em igualdade conforme buscado por movimentos de mulheres e feministas.

Alcançar o objetivo proposto implica ainda compreender a existência de construções sociais e do imaginário social em torno do que é "ser mulher", que limitam as possibilidades do ser. Zillah Eiseinstein (1979) e Helleith Saffioti (2015), feministas socialistas, serão trazidas com vistas a auxiliar na compreensão de como capitalismo e patriarcado se unem numa relação de simbiose subalternização das mulheres. A esfera privada é abordada, bem como as instituições que nela reside, para discutir os usos políticos e econômicos feitos do trabalho doméstico e de cuidados, que desemboca também no abordado na última seção da ressignificação da categoria trabalho para as mulheres.

Por último, buscando relacionar as categorias supracitadas, utilizaremos a Sociologia

\footnotetext{
${ }^{2}$ Para mais sobre a teoria (e o giro) decolonial na América Latina, ver Ballestrin (2013).
} 
do Trabalho e sua abordagem sobre as transformações e reestruturações do capital ocorridas com o neoliberalismo no fim do século XX e seu impacto no trabalho das mulheres bem como em sua inserção no mercado de trabalho. A entrada massiva de mulheres em áreas não consideradas tradicionalmente como femininas implicou a redução salarial e de prestígio social, conforme aponta Yannoulas (2011). Compreender esta ressignificação da subalternização das mulheres é fundamental para analisarmos o patriarcado como uma estrutura que não é estática. Assim, ao mesmo tempo em que aparenta ter perdido seu significado, o patriarcado se movimenta e modifica de acordo com as necessidades do capital e da dependência deste dos trabalhos desempenhados pelas mulheres na sociedade, tanto na esfera pública quanto na privada.

\section{Repensando Cidadania e Democracia: uma Ótica das Mulheres e da Justiça Social}

O recorte de gênero feito pelos movimentos feministas é sempre alvo de intensa discussão, como se a atuação em prol das mulheres fosse excludente em relação à sociedade como um todo e de privilégio das mulheres em detrimento dos homens. Esta seção tem o objetivo de abordar a necessidade de construir a igualdade a partir das diferenças, compreendendo as construções sociais em torno da cidadania e da democracia liberal, buscando apontar possibilidades de romper os moldes de gênero e avançar em termos de justiça social.

A cidadania foi construída e consolidada na democracia liberal representativa em torno da neutralidade, ao mesmo tempo em que universalizada com base num modelo de sujeito específico: o do "homem branco, adulto, urbano, burguês e heterossexual" (MOKRANIS, 2010, p. 108, tradução nossa). Essa pretensa universalidade nos transforma em cidadãs e cidadãos abstratos e se torna um mecanismo que desaparece com as nossas diferenças (de classe, de gênero, de etnia e tantas outras), desconsiderando as diferenças existentes nas relações sociais cotidianas e o peso e as condições materiais que resultam na sobrerepresentação de uns grupos à custa da sub-representação de outros. Portanto, a democracia tem papel de adentrar na trama de todas as relações sociais e não de desconsiderá-las, com papel questionador da separação das esferas pública e privada de modo a abordar de maneira profunda a formação dos governos e sua atuação (PHILLIPS, 1996 apud MOKRANIS, 2010).

Rita Segato (2012), autora decolonial, afirma "que o Estado entrega (...) com uma mão aquilo que já retirou com a outra” (p. 110), pois no momento de sua construção e consolidação enquanto poder político através de seu caráter colonizador e intervencionista, 
subjuga comunidades inteiras a partir de pressupostos que lhe são próprios, e, em contrapartida, exteriores a essas comunidades. Põe fim, portanto, à maneira como a comunidade se organizava, gerando um caos nas estruturas existentes e uma dependência para estas dessa organização que:

[...] oferece com uma mão a modernidade do discurso crítico igualitário, enquanto com a outra introduz os princípios do individualismo e a modernidade instrumental da razão liberal e capitalista, conjuntamente com o racismo que submete os homens não brancos ao estresse e à emasculação (ibid).

Segundo Segato (2012), pode-se sugerir que a esfera pública tem estreita relação com o processo colonizador, uma vez que é uma maneira de aprofundá-lo em nossas sociedades ainda nos dias de hoje. A autora retoma a categoria "contrato sexual" de Carole Pateman (1988), que nasce com vistas a problematizar as teorias clássicas do contrato social e seu silêncio acerca das transformações provocadas na vida das mulheres a partir da estrutura política estatal. Esta categoria poderia ser complementada pela ideia de que “(...) enquanto no mundo-aldeia o contrato sexual está exposto, na modernidade colonial o contrato sexual é disfarçado pelo idioma do contrato cidadão" (SEGATO, 2012, p. 118).

Pensar indivíduo enquanto categoria abstrata e universal é uma maneira de legitimação da exclusão e subalternização já existente de grupos específicos (como mulheres, negros, LGBTs, etc). Scott (2005) trata as identidades de grupo como "um aspecto inevitável da vida social e da vida política, e as duas são interconectadas porque as diferenças de grupo se tornam visíveis, salientes e problemáticas em contextos políticos específicos" (p. 18, grifos nossos). Esses contextos evidenciam as diferenças quando alguns grupos são favorecidos em detrimento de outros meramente a partir das características que possuem enquanto grupos. É nesse ponto que a igualdade formal se choca com a igualdade de fato, e nesse sentido que visamos problematizá-la.

Scott (2005) considera que os grupos são construídos socialmente a partir de padrões colocados por esta mesma sociedade ao longo de suas histórias com vistas a estabelecer significados de modo a limitar e conter suas possibilidades e, como resultado, coloca aqueles e aquelas que não se encaixam na norma como os diferentes. O silenciamento e a subalternização vão além: “"o indivíduo', (...) tem sido concebido em termos singulares e sido representado tipicamente como homem branco" (SCOTT, 2005, p. 23).

Tendo isso em vista, afirmamos que diversos grupos são excluídos com base nessa lógica ocidental, que é um dos pilares de nossa sociedade, de modo que amplificar a 
representação social significa reconhecer as diferenças, a composição social e especialmente enfrentar a complexidade resultante das relações sociais. A democracia deve nos tratar não como indivíduos, mas como pertencentes a determinado grupo cuja opressão e subalternização precisam ser destacadas de modo a suas características não serem objeto de discriminação (PHILLIPS, 1996 apud MOKRANIS, 2010).

Assim, a questão que se coloca é que a(s) diferença(s) existe(m) socialmente, mas a escolha a ser feita é de silenciá-la(s) ou considerá-la(s), compreendendo que sua desconsideração implica na escolha pela continuidade da discriminação social de determinados grupos. Essa consideração traz a existência de um paradoxo: a atenção se volta para a diferença e, embora tentando reduzir as assimetrias de grupos em termos de acesso aos direitos e de alcance da igualdade entre os indivíduos, reifica a identidade de grupo. Porém, esse paradoxo no nível dos grupos assume perspectiva diferente quando pensado do nível individual, uma vez que um indivíduo não é tratado como tal quando relacionado a determinado grupo, o que não o coloca em situação de igualdade de fato como insistem em argumentar (SCOTT, 2005).

Gênero trata das representações e imagens construídas - inter-relacionadamente - em torno do que é (ou não é) masculino e feminino. Apesar de parecer impossível o fim das dicotomias, pode-se coloca-las como sendo apenas o que são de fato: como sendo diferentes uma da outra. Segundo Saffioti (2015), “(...) diferente faz par com idêntico. Igualdade faz par com desigualdade, e são conceitos políticos (SAFFIOTI, 1997 apud SAFFIOTI, 2015, p. 124)". Nesse sentido, continua sua argumentação trazendo elementos sobre a diferença enquanto promotora da desigualdade, observado a partir ausência de mulheres em altos cargos, seja na política ou no setor empresarial, por exemplo. As experiências masculinas são historicamente distintas das femininas, quantitativa e qualitativamente, mas devido a essa desigualdade que é também histórica.

Afirma-se aqui o reconhecimento da diferença com intuito de praticá-la com uma finalidade positiva, visando desmascarar a naturalização da norma e retomar a pluralidade enquanto possibilidade que não seja excludente. É tratar de justiça social através do reconhecimento de que alguns grupos detêm privilégios e que a promoção de oportunidades para os grupos discriminados implica para aqueles a perda destes privilégios tradicionais. Nas palavras de Scott: “(...) a obtenção de equidade (ignorando genuinamente a diferença de acordo com os pilares do liberalismo) requer que se nomeiem os grupos que têm sido excluídos (reconhecendo a diferença) e que os tratem de forma diferenciada no futuro" (SCOTT, 2005, p. 27).

Aqui é importante retomarmos a análise de como o poder está constituído: a 
discriminação de determinados grupos não se dá no nível individual, isto é, aqueles que são privilegiados não escolhem discriminar os que não são. Esta é uma questão estrutural e um efeito inconsciente das estruturas de poder nas quais estamos inseridas e inseridos. A partir dessa perspectiva, o poder é um resultado de processos histórico-sociais em que a discriminação e a desigualdade se fortaleceram como algo dado e intransponível, perdendo de vista o que merece ser analisado com vistas a promover seu questionamento e, possivelmente, sua superação (SCOTT, 2005):

\begin{abstract}
A política tem sido descrita como a arte do possível; eu preferiria chamá-la de negociação do impossível, a tentativa de chegar a soluções que - em sociedades democráticas - aproximam os princípios da justiça e da igualdade, mas que só pode sempre falhar, deixando assim aberta a oportunidade de novas formulações, novos arranjos sociais, novas negociações (SCOTT, 2005, p. 29).
\end{abstract}

(Re)pensar os modelos de representação liberal nos parece, frequentemente, distante e impossível. A política tem sido comumente associada à uma falência deste modelo, cuja corrupção e subalternização de grupos tem sido cada vez mais evidenciados. Porém, não podemos negar a existência de tentativas de mudanças com vistas a inserir os grupos na política com maior equidade, mesmo que estas sejam tímidas, como a lei de cotas para mulheres no parlamento em diversos países ao redor do mundo. Entretanto, a noção abstrata de cidadania também se reflete aqui: a participação de mulheres na política significa a efetiva representação das mulheres?

Dunia Mokranis (2010) coloca algumas problematizações: a categoria mulher é suficientemente aglutinadora no enfrentamento das complexas relações de poder e resistências que hierarquiza grupos ou é outro instrumento que silencia diferenças de classe, etnia e sexualidade (para citar apenas algumas)? Como desconstruir a ideia de que as mulheres governam para os interesses das mulheres (argumento este facilmente falseado, como exposto na frase anterior) enquanto os homens governam com base nos interesses da nação (TAPIA, 2008 apud MOKRANIS, 2010)?

Essa noção de cidadania, além de homogeneizante, mostra-se despolitizadora. A ocupação de cargos institucionais se mostra uma possibilidade favorável, mas os avanços destas políticas precisam se dar em direção a um questionamento da estrutura em si e de seu papel na corroboração deste ambiente, masculinizado e excludente, muito mais que a mera inserção nesta estrutura: 
(...) consideramos que a descolonização ${ }^{3}$ supõe uma revisão dos próprios processos de cidadania para que os mesmos não convertam a tarefa política de fazer com que os excluídos ocupem o lugar de poder dos dominantes e para eles, cada vez mais queiram se assemelhar a eles, mas que estes processos permitam questionar esses lugares de poder a partir dos quais se construiu a exclusão (MOKRANIS, 2005, p. 114).

A estruturação da democracia liberal se dá em torno de representação, em que os grupos sem voz nos espaços políticos tem quase nenhum poder deliberativo, o que contribui para corroborar sua subalternização. Nesse sentido, questionar para transformar este caráter representativo de cima para baixo em que a sociedade tem pouco espaço é fundamental. Luis Tapia (2008 apud MOKRANIS, 2005) apresenta duas possíveis saídas, todas vinculadas a núcleos comunitários e culturais.

A primeira seria assumir a opressão de gênero e de classe como uma problemática no interior destes; a segunda estaria vinculada à criação de outros espaços de auto-organização dos movimentos de mulheres. Estas seriam maneiras de iniciar a organização de espaços de co-governo "entre homens e mulheres, entre diferentes culturas, o que implica alguma instância de deliberação e de democracia direta, como alternativa às mediações do esquema de representação liberal” (ibid, p. 116).

Os espaços liberais de representação, conforme se buscou apontar nesta seção, são percebidos mais como um lócus de reverberação de sub-representação das mulheres e de sua subalternização/exclusão do que um lócus emancipador de fato. A criação de espaços coletivos em que não impere a lógica liberal, mas uma lógica de construção coletiva, nos parece uma alternativa plausível.

O aprofundamento da democracia participativa, como defendido por Tapia (ibid) com a expansão dos espaços deliberativos comunitários aparece e o rompimento das mediações postas pela representação liberal, por conseguinte, com maiores possibilidades de pôr fim à subalternização e opressão das mulheres percebida na política atual. Por sua vez, Nancy Fraser traz importantes reflexões acerca da divisão das esferas pública e privada na medida em que deixam de ser meras designações de esferas da sociedade, colocando-as como "classificações culturais e rótulos retóricos que apresentam consequências prático-políticas importantes para a democracia" (MATOS, 2010, p. 70).

A divisão das duas esferas passa a ser vista, portanto, como geradora de exclusões e impeditiva quanto à garantia de direitos. A esfera privada passa a ser também assunto de Estado,

\footnotetext{
${ }^{3}$ As teorias que tratam acerca da descolonização a veem como um resultado político das colonialidades. Da mesma maneira se luta pela despatriarcalização, essas lutas não se dão separadamente devido à interseccionalidade e a relação categorial conforme Lugones (2008).
} 
apesar das dificuldades de sê-lo na prática, uma vez que o imaginário social perpassa pelo entendimento oposto. Conforme Biroli (2014, p. 46), "a garantia da privacidade depende da crítica à dualidade convencional entre o público e o privado e às desigualdades de gênero a que essa dualidade tem, tradicionalmente, correspondido".

Fraser apresenta a justiça de maneira tridimensional, através da: i) injustiça socioeconômica, em que a organização da estrutura político-econômica é vista como impeditivo para alguns e algumas terem acesso à plena participação política, se manifestando por privações materiais, marginalização e exploração; ii) injustiça cultural e simbólica, produto das construções e padrões sociais e culturais representativos, reconhecimento, interpretação e comunicação a partir dos quais se produz a marginalização de grupos minoritários; e iii) injustiça da representação política, "enraizada na constituição política da sociedade e que a injustiça correlata é a representação distorcida ou a afonia política”, dando enfoque para as estruturas governamentais e seus processos decisórios (FRASER, 2001, 2005 apud MATOS, 2010, p. 71). Sobre esta última dimensão:

\begin{abstract}
Segundo Fraser: "Estabelecendo critérios de pertencimento social e determinando quem conta como membro, a dimensão política da justiça especifica o alcance das demais dimensões: diz quem está incluído e quem está excluído do conjunto daqueles intitulados a uma justa distribuição e reconhecimento recíproco. Estabelecendo as regras de decisão, a dimensão política estabelece os procedimentos para colocar e resolver as disputas em ambas as dimensões econômica e cultural: diz não somente quem pode fazer demandas por redistribuição e reconhecimento, mas também como tais demandas devem ser colocadas e adjudicadas" (MATOS, 2010, p. 71).
\end{abstract}

Em outras palavras, o Estado passa a ser problematizado por outro viés, demonstrando que seu papel pode ser tanto do ponto de vista de justiça social quanto da corroboração do seu oposto. A inexistência de arenas democráticas para além do voto, no sentido de consultas e plebiscitos populares, por exemplo, impossibilita a participação e engajamento políticos, e, ao excluir a maioria da população das tomadas de decisão, dificulta também as tentativas de superação das injustiças, aprofundamento da democracia e participação na vida social.

Veronica Schild (2015), ao analisar o feminismo e o neoliberalismo na América Latina, questiona se a justiça de gênero não tem sido apenas uma "história de progresso da classe média", com ganhos no topo seguidos de indiferença para com a maioria das mulheres. Os impactos dos programas de reestruturação produtiva e ajustamento estrutural na periferia do capitalismo faz com que os avanços obtidos sejam ambíguos. O Estado cria secretarias de políticas públicas com vistas a reduzir as desigualdades ao mesmo tempo em que o caráter neoliberal de suas políticas econômicas e consequente abertura de mercados precariza ainda 
mais as relações de trabalho para as mulheres, como será abordado na última seção deste texto.

Nesse sentido, as diferentes dinâmicas do capitalismo neoliberal se desenrolam dentro de contextos sociais historicamente determinados de modo a produzir a multiplicidade de formas localizadas que estão em seus processos próprios de evolução contraditória, transitando de articulações experimentais para articulações mais maduras e consolidadas. Isso é acompanhado de diferentes processos de contestação pelo caminho. Com isso, tem-se que a explicação difusionista do avanço feminista oculta a pluralidade das experiências das mulheres e visa minar o potencial da teoria crítica feminista dos nossos tempos (SCHILD, 2015).

A partir do debate realizado nesta seção, buscou-se abordar como elas foram subalternizadas na esfera pública a partir da construção de suas cidadanias, discutiremos agora sobre os usos políticos da esfera privada e do trabalho que as mulheres desempenham nessa esfera.

\section{Capitalismo e Patriarcado: uma História de Amor?}

Esta seção tem o objetivo de demonstrar a complexa relação entre patriarcado e capitalismo e como esses dois sistemas se articularam de modo que se beneficiam da continuidade um do outro. Esses elementos serão articulados ainda a questões de raça, classe e sexualidade com vistas a trazer a perspectiva mais ampla de gênero buscada ao longo deste trabalho.

Utilizaremos uma definição de patriarcado desenvolvida por Zillah Eiseinstein (1979) em sua obra, para quem o patriarcado constitui um sistema sexual de poder que organiza a sociedade através da hierarquia masculina, conferindo privilégios econômicos e poder superior aos homens. Essas relações de poder são preservadas através do casamento, da família, da divisão sexual do trabalho e da sociedade. Desse modo, a hierarquização sexual da sociedade é um produto da utilização de interpretações ideológicas e políticas da diferença biológica, ou seja, do fato biológico de serem as mulheres as reprodutoras da sociedade, que resulta numa formulação específica de opressão delas (EISEINSTEIN, 1979).

O feminismo socialista proposto por Eiseinstein coloca o patriarcado como uma estrutura de poder que passa por transformações de acordo com o período histórico e as peculiaridades de cada sociedade, as quais ocorrem com vistas a proteger a hierarquia sexual da sociedade, resultantes de anos de pressão ideológica. Sobre isso, a relação é dialética: 
condições materiais definem ideologias necessárias, que por sua vez impactam e alteram a realidade. A autora afirma que, apesar de possuir características diferentes em cada sociedade a partir da maneira pela qual cada uma institucionaliza a hierarquia sexual, há uma característica do patriarcado que o torna transcultural: o poder deve estar e está com os homens (EISEINSTEIN, 1979).

O patriarcado é um caso específico de relações de gênero que abrange a sociedade como um todo, começando pela família na esfera privada atingindo até o direito patriarcal que afeta a sociedade civil e o Estado. Saffioti (2015) o trata como um recém-nascido frente a idade da humanidade, estimada entre 250 mil e 300 mil anos, enquanto gênero teve seu início nos últimos seis ou sete milênios. Na compreensão da autora, é necessária a articulação entre os dois conceitos, uma vez que gênero demonstra as hierarquias entre as categorias de sexo, mas não visibiliza os perpetradores do controle e da violência, centrais na cultura gerada pela dominação-exploração ${ }^{4}$ patriarcal (ibid).

A compreensão do patriarcado se dá de maneira estrutural, em que afeta o comportamento dos indivíduos muitas vezes de modo inconsciente, pela construção social desse poder dos homens em detrimento das mulheres. Saffioti o define como uma:

Estrutura hierárquica, que confere aos homens o direito de dominar as mulheres, independentemente da figura humana singular investida de poder. Quer se trate de Pedro, João ou Zé Ninguém, a máquina funciona até mesmo acionada por mulheres. (...) ainda que não sejam cúmplices deste regime, colaboram para alimentá-lo (SAFFIOTI, 2015, p. 108).

O patriarcado, através da divisão sexual do trabalho, se manifesta de forma material por meio dos papeis dos sexos e na realidade ideológica pelos estereótipos, mitos (criados e consolidados em torno de uma imagem específica das mulheres. Eiseinstein considera a divisão sexual do trabalho o mecanismo básico de controle para a cultura patriarcal, uma vez que é responsável pela hierarquização social entre papeis masculinos e femininos ${ }^{5}$ no

\footnotetext{
4 “A dominação-exploração constitui um único fenômeno, apresentando duas faces. Desta sorte, a base econômica do patriarcado não consiste apenas na intensa discriminação salarial das trabalhadoras, em sua segregação ocupacional e em sua marginalização de importantes papeis econômicos e político-deliberativos, mas também no controle de sua sexualidade e, por conseguinte, de sua capacidade reprodutiva. Seja para induzir as mulheres a ter grande número de filhos, seja para convencê-las a controlar a quantidade de nascimentos e o espaço de tempo entre filhos, o controle está sempre em mãos masculinas, embora elementos femininos possam intermediar e mesmo implementar estes projetos" (SAFFIOTI, 2015, p. 113).

${ }^{5}$ Por outro lado, Saffioti aborda que gênero enquanto significado do feminino e do masculino dentro das sociedades sempre existiu. Nas sociedades de caça e coleta, por exemplo, a organização dos trabalhos se deu com base na necessidade do aleitamento dos bebês, à época feita apenas com o bebê ao seio da mãe. Segundo Lerner (apud SAFFIOTI, 2015, p. 64), "o menor sussurro do bebê espantaria o animal destinado à morte e as caçadoras voltariam, invariavelmente, para seu grupo, sem nenhum alimento". Em contra partida, Lerner cita também sociedades em que as mulheres eram responsáveis pela caça de focas. Esses exemplos tem o intuito de
} 
capitalismo, o que significa dizer que papeis, propósitos, atividades e inclusive o trabalho de cada uma e um são determinados pelo sexo. A distinção biológica homem/mulher é utilizada, portanto, como meio de diferenciar funções sociais e o poder individual, o que torna sexo uma categoria com implicações políticas (EISEINSTEIN, 1979).

A divisão sexual do trabalho é utilizada pelo patriarcado ainda para estabelecer o trabalho de reprodução, ou seja, o trabalho doméstico (e, portanto, não remunerado). Este inclui o trabalho que as mulheres desempenham ao se tornarem mães no cuidado com a casa e com os filhos como sendo tarefas exclusivamente femininas, quase que uma obrigação devido a sua função de reprodutoras. Portanto, é fundamental para a reprodução do sistema capitalista patriarcal e para a manutenção da desigualdade entre gêneros.

Por sua vez, a família é utilizada como uma necessidade histórica para limitar as mulheres à vida privada, fazendo com que a produção, a reprodução, a sexualidade e a socialização dos filhos definam o propósito econômico e social das mulheres, além de excluílas da produção e da vida pública (EISEINSTEIN, 1979). Sobre isso, Pateman (1993 apud SAFFIOTI, 2015) destaca o fato de que a consciência que as mulheres têm de si mesmas advém de sua inserção enquanto mulheres e esposas na estrutura social, e não da socialização que recebem. É nesse sentido que afirmamos o papel das estruturas patriarcais na corroboração das relações desiguais de gênero, cerceando as possibilidades e escolhas dos indivíduos a partir da construção social do que é designado para estes através do gênero.

Assim, a divisão sexual da sociedade atua fortemente também aqui, dividindo e hierarquizando homens e mulheres a partir de seus deveres dentro da família e da economia. A imagem masculina foi tradicionalmente construída em torno da responsabilidade pelo sustento econômico da família enquanto a feminina se relaciona ao cuidado da casa e dos filhos. Essa concepção do núcleo familiar exclui mulheres que não sejam heterossexuais, uma vez que essa estrutura implica que o casal seja formado por um homem e uma mulher (portanto, heterossexuais), de modo que cada um exerça seus respectivos papeis.

Embora a divisão sexual do trabalho e da sociedade preceda o capitalismo, é neste sistema que se institucionaliza mais concretamente em torno da família, se adaptando às necessidades do capitalismo chamado de "avançado", em que o consumo familiar é importante para sua continuidade. Nesse sentido, todos os processos relacionados ao trabalho doméstico são fundamentais para a continuidade desse modelo de sociedade da seguinte forma:

evidenciar que a existência da divisão sexual do trabalho não implica na desvalorização das atividades socialmente atribuídas às mulheres em relação às dos homens como, ao contrário, se dá no que chamamos aqui de capitalismo patriarcal (SAFFIOTI, 2015). 
(1) As mulheres estabilizam as estruturas patriarcais (a família, a dona de casa, a mãe, etc) preenchendo esses papeis. (2) Simultaneamente, as mulheres estão reproduzindo novos trabalhadores, tanto para a força de trabalho remunerada quanto para a nãoremunerada. Elas cuidam dos homens e das crianças da sociedade. (3) Elas também trabalham por salários menores. (4) Elas estabilizam a economia através do seu papel como consumidoras. Se um lado da produção é o consumo, o outro lado do capitalismo é o patriarcado (EISEINSTEIN, 1979, p. 29, tradução nossa).

Patriarcado e capitalismo trabalham conjuntamente formando a economia política da sociedade: o patriarcado desenvolve a hierarquização sexual para controle político das mulheres "enquanto o capitalismo como um sistema de classe econômica impulsionada pela busca do lucro alimenta a ordem patriarcal” (EISEINSTEIN, 1979, p. 28, tradução nossa). Este controle, entretanto, precisou passar por adaptações ao longo do desenvolvimento capitalista, que incluiu a entrada das mulheres no mercado de trabalho, não estando agora completamente limitadas à esfera privada não-remunerada.

Porém, essa entrada não implicou a emancipação das mulheres, percebida na nãointegração total das mulheres nas diferentes partes da força de trabalho, na consideração de que são mão de obra barata, na diferenciação salarial entre mulheres brancas e mulheres negras, que demonstra também a apropriação capitalista das opressões de gênero e raça. A continuidade de seus papeis enquanto responsáveis pelo trabalho doméstico, ainda não remunerado nem reconhecido como trabalho, faz com que as mulheres adquiram dupla função (e jornada de trabalho): a de donas de casa e de proletárias, "e os dois trabalhos são feitos por menos que o preço de um" (EISEINSTEIN, 1979, p. 29, tradução nossa).

A divisão sexual do trabalho é, portanto, uma maneira de estabilizar a sociedade através da família. Essa estabilidade se dá pela organização do "trabalho, trabalho doméstico pelo qual não há pagamento (donas de casa) ou este é limitado (donas de casa remuneradas) ou pagamento desigual (na força de trabalho remunerada)" (EISEINSTEIN, 1979, p. 30, tradução nossa). A diferenciação salarial é sintomática quanto ao efeito da divisão sexual do trabalho sobre as mulheres numa sociedade capitalista patriarcal, "reflexo direto das divisões sexuais hierárquicas em uma sociedade organizada em torno da motivação do lucro" (ibid.).

Por conseguinte, os homens são privilegiados por essa organização da sociedade, mesmo que de forma diferente devido às opressões de classe, raça e sexualidade, que atuam produzindo um sistema de privilégios. Enquanto isso, todas as mulheres são afetadas, mas de maneiras diferentes a depender também de classe, raça e sexualidade, se desempenham trabalhos remunerados (em que pesa serem formais ou informais, por exemplo) e se são casadas e heterossexuais (em que pesa a reprodução do capitalismo como supracitado) (EISEINSTEIN, 
1979).

Tendo em vista o debate das duas últimas seções, passaremos agora à discussão sobre o neoliberalismo e seu impacto para as mulheres latino-americanas. Com isso busca-se abordar como também o mercado de trabalho se orienta a partir da divisão sexual do trabalho e limita (assim como desvaloriza) as possibilidades das mulheres neste âmbito.

\section{O Neoliberalismo e a vida das Mulheres Latino-americanas}

Com o discurso da busca por qualidade, flexibilidade e alta produtividade ao menor custo, o neoliberalismo gerou um processo de reestruturação produtiva com profundo impacto nas relações de trabalho a partir dos novos métodos de gestão do trabalho e da produção. A globalização, também chamada por Chesnais (1997) de mundialização do capital, tem estreita ligação com o neoliberalismo. Essa mundialização teve grande participação do Estado e suas políticas neoliberais dos anos 1990, observadas na desregulamentação e abertura dos mercados a partir das multinacionais e de seus pressupostos de privatizações, sub-contratação e externalização da produção em busca de mão-de-obra barata (HIRATA, 2001; ARAÚJO, 2007).

Essa reestruturação do capital certamente não era a única possível, e nesse sentido é relevante retomar a importância das decisões dos atores a elas relacionados, como foi o caso do empresariado e do Estado. Essas decisões afetaram as relações de trabalho de tal maneira que passaram a trazer distintos sentidos do trabalho das mulheres (ARAÚJO, 2007). Assim, tendo em vista os impactos das decisões político-econômicas no mundo do trabalho, acreditamos que as políticas estatais adotadas neste período são uma demonstração de seu caráter patriarcal e excludente.

Por outro lado, as novas tecnologias de informação e comunicação possibilitaram a financeirização das economias com o uso da circulação imediata de informações e dados. Há ainda o novo papel dos organismos internacionais de papel regulador paralelamente ao Estado e às firmas internacionais, que nem sempre se dão na mesma direção. Esse contexto econômico, financeiro e político tem impactos diferentes de acordo com a região geográfica, afetando "a divisão sexual do emprego, do trabalho - profissional e doméstico - e da atividade dos homens e das mulheres" (HIRATA, 2001, p. 143).

Entre 1960 e 1970, houve um aumento significativo da participação das mulheres no mercado de trabalho, aumentando o número de mulheres economicamente ativas de 18 para 57 milhões. Enquanto a taxa de participação feminina na População Economicamente Ativa 
(PEA) aumentou 9,1\%, a masculina diminuiu 7,2\%. Essa participação das mulheres, entretanto, se expressa em trabalhos precários e vulneráveis com aumento do desemprego de longo prazo, que gera a necessidade de outras formas de emprego e de flexibilidade no uso da força de trabalho como forma de busca pela sobrevivência, especialmente na América Latina e em regiões como Ásia e Europa (ABRAMO, 2001; HIRATA, 2001).

O setor de serviços e as novas profissões em torno deste, um dos que mais cresceu nesse contexto de perda de direitos e de crise econômica e recessão, tem cor, classe e gênero, impactando em especial a vida de mulheres indígenas, negras e pobres. Além dos baixos salários, da inexistência de reconhecimento e valorização social advindos dessa precarização do trabalho em que se inserem as "trabalhadoras ditas de "baixa qualificação"” (HIRATA, 2001, p. 148), pesa também a questão da saúde no trabalho. Segundo Araújo (2007), há altos índices de Lesão por Esforço Repetitivo (LER) entre as trabalhadoras de setores com intensificação do ritmo de trabalho em tarefas simples e repetitivas - que nessas características se parecem em muito com as tarefas domésticas, naturalizadas e ambas não reconhecidas como qualificadas pelas empresas.

O processo de reestruturação produtiva é tratado por Lemos \& Ferreira (2010) como um dos fatores que potencializou maior inserção das mulheres do mercado de trabalho. Esta inserção veio associada a uma lógica de precariedade a despeito de modificações, relacionadas especialmente à maior inserção de mulheres nas universidades e consequente aumento na força de trabalho qualificada feminina percebida nos anos 90, também provenientes das lutas pela emancipação feminina a partir dos anos 60 .

Segundo estudos realizados por Laís Abramo (2001), o aumento no nível de educação e de participação das mulheres no mercado de trabalho significou um aumento na sua participação no grupo de profissionais e técnicos. Este aumento no nível educacional se deu de tal maneira a ser mais elevado que o dos homens, devido à necessidade de mais anos de estudo para as mulheres se incorporarem ao mercado de trabalho.

No mesmo estudo a autora afirma que a taxa de desemprego feminina segue maior que a masculina. Esse aspecto é o que faz com que aumente sistematicamente a proporção de mulheres em trabalhos precários, o que implica em baixos salários, baixa produtividade, ausência de contratos, ausência de proteção social, assim como o aumento ou o retorno de antigas formas de ocupação. É o caso das "novas" modalidades de trabalho em domicílio, eventual, em tempo parcial ou subcontratado (ABRAMO, 2011).

O emprego doméstico continua sendo exercido predominantemente pela força de trabalho feminina e negra, como um elemento do sistema moderno/colonial de gênero 
(LUGONES, 2008), em que famílias das classes média e alta atribuem a realização das tarefas domésticas para mulheres de classes baixas em situação bastante insegura e precária na maioria das vezes. Apenas em 2015 se iniciou a legislação trabalhista para empregadas domésticas, que gerou reação dos setores conservadores da sociedade, apesar de significar a garantia de direitos trabalhistas mínimos, já conquistados há muito tempo pela classe trabalhadora de modo geral: carteira de trabalho assinada e previdência social (PINHEIRO et al, 2016).

A atividade permanece como a principal ocupação entre as mulheres negras (17,7\% das mulheres negras eram trabalhadoras domésticas em 2014, número que cai para $10 \%$ no caso das mulheres brancas), mesmo que tenha havido uma queda no percentual de mulheres inseridas nessa atividade desde 2004. Essa redução tem relação com a queda contínua no número de trabalhadoras domésticas jovens, geralmente as mais escolarizadas, possivelmente devido à estigmatização da profissão, os baixos salários (apesar da percepção do aumento nestes com a ampliação da formalização) e proteção social (percebidos notadamente pelo alto índice de trabalhadoras sem carteira de trabalho assinada). Além disso, a discriminação e a exploração as leva a buscarem inserção em outros setores do mercado de trabalho (hipótese reforçada pela persistente baixa escolaridade das trabalhadoras domésticas) ou a permanecer na desocupação. Assim, além da baixa escolaridade, a informalidade marca fortemente a categoria (PINHEIRO et al, 2016).

Essa tendência ao envelhecimento da profissão tem também a marca racial, na medida em que se deu muito mais rapidamente para as mulheres brancas em relação às negras. No Brasil, no período de 2004 a 2013, o percentual de trabalhadoras domésticas brancas até 29 anos foi de $30 \%$ a $10 \%$, de brancas de 45 anos ou mais foi de cerca de $28 \%$ a $50 \%$, enquanto de negras até 29 anos foi de $40 \%$ a cerca de $20 \%$ e de negras de 45 anos ou mais foi de $20 \%$ a $40 \%$. Além disso, tem-se observado o aumento do número de trabalhadoras que oferecem serviços em mais de uma residência, corroborando com as relações desiguais de trabalho (PINHEIRO et al, 2016).

Tendo isso em vista, a sociologia do trabalho vem dar destaque às "relações concretas de desigualdade, opressão e discriminação da força de trabalho feminina", também com vistas a, em certa medida, superá-las (LEMOS \& FERREIRA, 2010, p. 9). Daí advém a associação entre técnicas tayloristas de produção e a divisão sexual do trabalho. O taylorismo aprofunda a divisão do trabalho pelo fracionamento das etapas produtivas em tarefas especializadas, que seria impensável sem a organização social em torno da divisão sexual do trabalho, especialmente neste modo de produção cujo racionalismo do trabalho demanda forte disciplina e controle dos corpos, profundamente ligados às operárias. 
Segundo Hirata (2001), “o rigor e disciplinamento no local de trabalho entre as mulheres são facilitados pelo fato de que são socializadas tendo por base a docilidade e obediência" (LEMOS \& FERREIRA, 2010, p. 8). A divisão sexual do trabalho é vista pela autora e por Souza-Lobo como "procedimento que cria guetos profissionais específicos e sexuados" (ibid, p. 9), em que a reestruturação produtiva permitiu maior inserção feminina no mercado de trabalho, mas com forte fragmentação dos postos de trabalho a partir das relações de gênero.

Para Yannoulas (2011), a divisão sexual do trabalho e sua manifestação no mercado de trabalho segmentam-no em dois sentidos. No horizontal, em que a maioria das trabalhadoras está inserida em poucas profissões e ocupações, e no vertical, em que um baixo número de mulheres ocupa altos cargos, mesmo considerando os setores em que a participação feminina é maior que a masculina como é o caso da educação, da saúde e do serviço social. Percebe-se, então, a hierarquização dos papeis masculinos em detrimento dos femininos.

Assim sendo, o setor de prestação de serviços, comumente associado com a força de trabalho feminina, não possibilita a ascensão da carreira dessas mulheres, além de ser caracterizado por sua pouca duração e pela falta de garantias em termos de direitos trabalhistas e previdenciários. Nesse sentido, segundo Abramo (2004), há que se pensar o peso que as imagens de gênero, discutidas nas seções anteriores, tem na manutenção e reprodução das desigualdades no mundo do trabalho, construídas em torno de um mecanismo dicotomizador que assinala lugares e funções diferentes e hierarquizadas entre homens e mulheres. $\mathrm{Na}$ prática, isso se manifesta através da imagem da mulher como cuidadora da casa enquanto o homem é visto como o provedor financeiro desta.

A participação feminina no mundo do trabalho ainda é vista como uma força de trabalho secundária (com o salário da mulher encarado como renda complementar à do homem) além de instável (sua inserção neste mundo se dá por uma "falha" no cumprimento do papel do homem enquanto provedor). Isso faria a mulher abandoner seu trabalho assim que possível para "voltar" a seu papel na esfera privada e doméstica. Tem-se ainda a ideia de que o comportamento trabalhista das mulheres é pouco adequado devido à suas preocupações com a família que as fariam ter altos níveis de absenteísmo. Entretanto, estudos demonstram o crescente número de mulheres como provedoras financeiras de suas famílias, além de nunca tenha havido evidências quanto a esse suposto absenteísmo maternal: a maioria das mulheres não para de trabalhar quando tem filhos como acontecia em tempos passados (ABRAMO, 2001, 2004, YANNOULAS, 2011).

Nesse sentido, Yannoulas (2011), traz que a participação das mulheres no mercado de 
trabalho na virada do século XIX para o XX, apesar de ter sido tolerada, foi muito controlada especialmente a partir dos papeis de gênero e da percepção da maternidade, do cuidado e da preservação do núcleo familiar como a principal função das mulheres. Estas são estruturas patriarcais que corroboram com a opressão de gênero, conforme Eiseinstein (1979). Apesar de Yannoulas tratar de outro contexto, é possível perceber como a conjuntura do neoliberalismo ainda o faz da maneira muito parecida: se apropriando de sua força de trabalho (remunerada e não-remunerada) sem que isso signifique transformações em termos de igualdade nas relações sociais de gênero, nem a valorização de seu trabalho.

Sobre o tema, a autora traz dois conceitos: feminização e feminilização. Para ela, o ingresso massivo de mulheres num determinado segmento caracteriza a feminilização, acompanhado pela redução da remuneração e do prestígio social do trabalho em questão, caracterizando a feminização. Assim, a feminização é a mudança na existência objetiva de determinada profissão a partir do acesso massivo de mulheres nesta, como é o caso, de acordo com este trabalho, do processo de reestruturação produtiva (YANNOULAS, 2011).

Apesar das transformações da participação das mulheres no mundo do trabalho, a divisão sexual do trabalho e o trabalho reprodutivo se mantiveram quase que intactos em termos de serem predominantemente de responsabilidade das mulheres. Estudos afirmam que em 2014, no caso do Brasil, a divisão sexual do trabalho gera uma diferença de 14,4 horas semanais no tempo que as mulheres (em relação aos homens) se dedicam às atividades domésticas (PINHEIRO et al, 2016). Além de demonstrar a relevância da ruptura da dicotomização dos espaços públicos e privados, isso é um reflexo da dupla jornada de trabalho já referida neste trabalho, da qual se beneficia o capitalismo patriarcal para a manutenção deste sistema.

A invisibilização desta atividade se encontra também na produção de estatísticas do Brasil pelo Instituto Brasileiro de Estatística e Geografia (IBGE), em que a produção de bens e serviços não remunerados no mundo privado é entendida como atividade não produtiva. Isso dá a condição de inativo a quem as exerce no caso de não terem atividade no mercado de trabalho (PINHEIRO et al, 2016).

Segundos dados das Pesquisas Nacionais por Amostra de Domicílios (Pnad) do IBGE de 2014, as mulheres tem índices maiores de taxas de desocupação quando comparadas aos homens (cerca de $8,5 \%$ pelas elas e de $5 \%$ para eles). Se discriminarmos a partir da raça, esse número sobe para $10,2 \%$ no caso das mulheres negras e desce para $4,5 \%$ no caso dos homens brancos, indicando a suscetibilidade daquelas ao desemprego. Além disso, 44,2\% das mulheres negras não contribuem para a previdência social, o que desprotege ainda mais esse setor social, o qual tem $39,1 \%$ de sua força de trabalho inserida em relações precárias de trabalho. Enquanto 
isso, os homens negros tem $31,6 \%$, as mulheres brancas $27 \%$ e os homens brancos $20,6 \%$, demonstrando a estratificação social com base na renda que coloca a mulher negra na base do sistema remuneratório, ocupando as piores ocupações, resultante da interseccionalidade das opressões de gênero, raça e classe (PINHEIRO et al, 2016).

Mesmo num período de expansão econômica e de ampliação da formalização das relações de trabalho, como aconteceu entre 2004-2014, não há reversão das divisões sexual e racial do trabalho e estes setores da sociedade se inserem nessas relações de maneiras cada vez mais precárias, ao contrário do que se poderia esperar (PINHEIRO et al, 2016). A entrada das mulheres no mercado de trabalho não provocou sua emancipação, mas sim a adaptação deste sistema com vistas a encontrar novos meios de exploração de grupos subalternos. Assim, a entrada massiva de mulheres no mercado de trabalho não afetou:

a hierarquia das desigualdades profissionais em termos de prestígio social, remunerações ou potencial perda de emprego, pois não foram capazes de alterar o tipo de carreira profissional, o qual é pautado, geralmente, pelo modelo do profissional masculino ou, dito em outros termos, pelas possibilidades concretas dos homens no exercício das respectivas profissões (YANNOULAS, 2003 apud YANNOULAS, 2011, p. 286).

O novo modelo de flexibilização na América Latina traz consigo formas de emprego precárias, contratos de curta duração, empregos em tempo parcial e/ou trabalho a domicílio para as mulheres. A presença feminina se dá majoritariamente nas empresas "mãos" dos novos encadeamentos produtivos, caracterizados pelo trabalho instável, pouco qualificado e mal pago, enquanto o trabalho mais bem qualificado, estável e mais bem-remunerado das empresas "cabeça" tem participação majoritariamente masculina (Castillo \& Santos, 1993 apud Abramo, 2001). Nesse sentido Abramo (2001) argumenta da necessidade de análise das cadeias produtivas para compreender a fundo como essas relações de trabalho modificadas têm impacto na forma como a força de trabalho feminina se insere nelas.

Conforme Yannoulas (2011, p. 288): "a polêmica sobre a feminização dos processos sociais não é apenas epistemológica, mas fundamentalmente política". Por isso, é essencial desnudar as relações de trabalho a partir do espaço reduzido e desprestigiado que as mulheres ocupam, assim como os processos de precarização, flexibilização e desvalorização que vieram com a entrada massiva de mulheres em determinadas atividades e setores. 


\section{Conclusão}

Os feminismos em suas diferentes abordagens e perspectivas teórico-práticas têm ganhado força nos últimos tempos na sociedade como um todo, seja nas redes sociais, seja nos programas de televisão ou nas pesquisas acadêmicas. Este artigo foi um esforço de trazer diferentes abordagens que, em última instância, nos ajudam a compreender como é possível no neoliberalismo, processo histórico relativamente recente, a ressignificação da opressão das mulheres e da desvalorização dos trabalhos realizados pore las, mesmo no mercado de trabalho.

Os processos de limitação das mulheres à esfera privada foram atrelados à divisão sexual do trabalho bem como à produção de mão-de-obra para o capitalismo patriarcal. Procurou-se evidenciar como as mulheres são socialmente construídas para preencherem papeis sociais que as subalternizam e contribuem com a continuidade da própria opressão e das engrenagens deste sistema: como donas de casa, mães e, até mesmo, como trabalhadoras.

A questão de justiça social na esfera econômica em termos de mercado de trabalho aponta para a inferiorização de trabalhos realizados majoritariamente por mulheres. Isso reforça a mutualidade entre capitalismo e patriarcado: num contexto de necessidade de força de trabalho, o patriarcado cede quanto à entrada das mulheres em setores não tradicionais à elas, enquanto o capitalismo se apropria de mais um trabalho executado por elas, também através da redução de salários e de prestígio social.

Em termos políticos, cidadania e democracia aparecem como conceitos que foram esvaziados e despolitizados em prol da suposta existência de homogeneidade em torno do ideal de que somos todos iguais perante à lei. Debater o aprofundamento de ambas as noções é também aprofundar os direitos das mulheres e pressionar a política nos termos da negociação do impossível, conforme Scott (2005).

Nesse sentido, trazer as narrativas das mulheres para a ótica de análise implica na realização do debate em outros termos. Contextos políticos importantes como o neoliberalismo não podem passar despercebidos quanto aos impactos específicos que geram nas mulheres e na corroboração deste grupo enquanto subalternizado. Trazer a perspectiva feminista implica tanto na busca profunda pelas raízes da opressão de gênero quanto no fornecimento de maneiras de compreender como essa mesma opressão se modifica e se adapta a conjunturas aparentemente neutras quanto à gênero - demonstrar que, ao menos atualmente, tal situação não existe, persiste uma tarefa árdua para nós, feministas.

A divisão sexual do trabalho nos parece hoje algo estático e dado, como se sempre 
houvesse existido da seguinte forma: as mulheres fazem o trabalho doméstico e de cuidados enquanto os homens seguem provendo o dinheiro para a família. A ressignificação deste papel pelas mulheres, isto é, sua entrada no mercado de trabalho e o crescente número de chefes de família, não foi acompanhada por uma ressignificação de como a sociedade as enxerga e dos papeis que se espera que estas ocupem. Em última instância, é também a partir dessas bases que o capitalismo patriarcal encontra espaço para reproduzir e ressignificar a opressão de gênero a ponto naturalizá-la a cada dia e fazê-la passar despercebida aos olhos de muitos e muitas - diversas vezes, mesmo das que a vivem.

\section{Referências Bibliográficas}

ABRAMO, Laís. Inserción Laboral de Las Mujeres en América Latina: una Fuerza de Trabajo Secundaria? In: Estudos Feministas, Florianópolis, v. 12, n. 2, Maio-Ago, 2004.

A Situação da Mulher Latino-Americana: o Mercado de Trabalho no Contexto de Reestruturação. In: Proposta, n. 88/89, Mar/Ago, 2001.

ARAÚJO, Angela Maria Carneiro. Trabalho, Precarização e Relações de Gênero em Tempos de Flexibilização e Reestruturação Produtiva. In: XIII CONGRESSO BRASILEIRO DE SOCIOLOGIA, 2007, Recife. Anais..., Recife: Sociedade Brasileira de Sociologia, 2007.

BIROLI, Flávia; MIGUEL, Luis Felipe. Feminismo e Política: uma introdução. $1^{\text {a }}$ ed. São Paulo: Boitempo. 2014.

EISEINSTEIN, Zillah. Developing a Theory of Capitalist Patriarchy and Socialist Feminism. In: Capitalist patriarchy and the case for socialist feminism. Zillah Eiseinstein (org), New York: Westview Press, 1979.

FRASER, Nancy. Reframing Justice in a globalizing world. In: New Left Review, London, n. 36, p. 69-88, 2005.

Da redistribuição ao reconhecimento? Dilemas da justiça na era pós-socialista. In: SOUZA, J. (org.). Democracia hoje: novos desafios para a teoria democrática contemporânea. Brasília: UNB, 2001.

HIRATA, Helena. Globalização e Divisão Sexual do Trabalho. In: Cadernos Pagu, $\mathrm{n}^{\circ}$ 17/18, pp.139-156, 2001.

LANDER, Edgardo (org). Colonialidade do Saber: Eurocentrismo e Ciências Sociais. Perspectivas latinoamericanas. In: Colección Sur Sur, CLACSO, Ciudad Autónoma de Buenos Aires. Argentina, 2005.

LEMOS, Marcelo Rodrigues; FERREIRA, Eliane Schmaltz. A construção social do gênero e o rompimento do caráter assexuado das relações de trabalho. In: III Seminário Nacional de Trabalho e Gênero, Goiânia, 2010. 
MATOS, Marlise. Movimento e Teoria Feminista: É Possível Reconstruir a Teoria Feminista a Partir do Sul Global? In: Revista de Sociologia e Política, Curitiba, v. 18, n. 36, jun, 2010.

MOKRANIS, Dunia. Reflexiones sobre la representación y participación política de las mujeres en el marco de un proceso de descolonización de la sociedad y el Estado. In:

Despatriarcalizar para descolonizar la gestión pública. CHÁ VEZ, Patricia; Tania, QUIROZ; LUGONES, María (org.), Vice presidencia del Estado Plurinacional de Bolivia Dirección de Participación Ciudadana, La Paz, Bolivia. 2010

PINHEIRO et al. Mulheres e Trabalho: breve análise do período 2004-2014. In: Nota Técnica, IPEA (Instituto de Pesquisa Econômica Aplicada), n. 24, Brasília, mar, 2016.

QUIJANO, Aníbal. Colonialidad del poder, eurocentrismo y América Latina. In: LANDER, E. (org) La colonialidad del saber: eurocentrismo y ciencias sociales. Perspectivas Latinoamericanas. CLACSO, Buenos Aires, Jul, 2000.

SAFFIOTI, Heleieth. Gênero, patriarcado e violência. 2 ed. São Paulo: Expressão Popular, Fundação Perseu Abramo, 2015.

SCHILD, Verónica. Feminism and Neoliberalism in Latin America. In: New Left Review, v. 96, nov-dez, 2015.

SCOTT, Joan. O enigma da igualdade. In: Revista Estudos Feministas, v. 13, n. 1, 2005.

SEGATO, Rita Laura. Gênero e colonialidade: em busca de chaves de leitura e de um vocabulário descolonial. Em: e-cadernosces [Online] v. 18, 2012.

TICKNER, J. Ann. You Just Don't Understand: Troubled Engagements Between Feminists and IR Theorists. In: International Studies Quarterly, v. 41, 1997.

YANNOULAS, Silvia. Feminização ou Feminilização? Apontamentos em Torno de uma Categoria. In: Temporalis, Brasilia, v. 11, n. 22, jul.-dez, 2011. 